\title{
Dentro e Fora da Caixa Preta: A Mente sob um Olhar Evolucionista ${ }^{1}$
}

\author{
Maria Lucia Seidl de Moura ${ }^{2}$ \\ Universidade do Estado do Rio de Janeiro
}

\begin{abstract}
RESUMO - Este trabalho visa apresentar uma breve história da concepção da mente nas últimas décadas, e discutir modelos evolucionistas de mente. São enfocados o movimento cognitivista, em que a mente é protagonista, e a psicologia evolucionista, que resgata a história filogenética. Diferentes modelos, modulares e os que incluem processos centrais, são apresentados. É discutida a importância de se considerar a ontogênese e duas perspectivas ontogenéticas são apresentadas. Conclui-se com uma visão otimista da direção dos esforços contemporâneos de compreensão da mente humana, propondo a integração de aspectos dos modelos apresentados.
\end{abstract}

Palavras-chave: mente; cognição; arquitetura da mente; psicologia evolucionista.

\section{In and Out the Black Box: The Mind on an Evolutionary Perspective}

\begin{abstract}
This article aims to present a brief history of conceptions of mind in the last decades and to discuss evolutionary models of mind. The cognitivist movement, in which the mind is the protagonist, and evolutionary psychology, in which the philogenetic history of mind is contemplated, are focused. Different models, modular and including central processes, are presented. The importance of considering ontogenesis is discussed, and two ontogenetic perspectives of the mind are presented. The conclusion about the direction of the contemporary efforts of comprehension of the human mind is optimistic, with the proposition of integration of aspects of the models presented.
\end{abstract}

Key words: mind; cognition; architecture of mind; evolutionary psychology.

Em pouco mais de um século desde a fundação da psicologia científica, o conhecimento da mente humana tem avançado em um movimento nem sempre linear. Ora objeto da psicologia, ora colocada na caixa preta, a mente humana tem sido muitas vezes considerada por visões que privilegiam um ou outro dos múltiplos aspectos de sua constituição. Contemporaneamente, no entanto, assiste-se a buscas de compreensão da imbricação entre aspectos biológicos e culturais, psicológicos e neurológicos, entre emoção e razão, numa visão da mente como produto da seleção natural na evolução da espécie do Homo sapiens sapiens. Um grupo de pesquisadores brasileiros tem coordenado seus esforços e perspectivas, buscando integrar e discutir as evidências das pesquisas de diversas disciplinas (antropologia, etologia, primatologia, psicologia, etc.) no sentido de uma compreensão evolucionista da mente humana, em sua filogênese e ontogênese. Esses pesquisadores são membros do grupo de trabalho sobre psicologia evolucionista, da Associação Nacional de Pesquisa e Pós-graduação em Psicologia (ANPEPP) coordenado por Maria Emilia Yamamoto e Emma Otta. Esse

1 Uma primeira versão dessas idéias foi apresentada em sessão da Reunião Anual da Sociedade Brasileira de Psicologia, em 2004. A autora agradece a diversos interlocutores com quem discutiu as idéias aqui apresentadas, ao longo dos anos: ao Prof. Antonio Gomes Penna, por tudo que com ele aprendeu, inclusive sobre o movimento cognitivista; a Eulina Lordelo, pela indicação do trabalho de Barkow, Tooby e Cosmides; a Emma Otta e Vera Silvia Raad Bussab, por compartilharem seu conhecimento sobre a filogênese e psicologia evolucionista; a Angela Donato Oliva pelas estimulantes discussões relâmpago, realizadas entre as múltiplas atividades acadêmicas das duas, e pelo incentivo para a publicação desse artigo; e ao CNPQ, pelo apoio com bolsa de produtiidade e grant.

2 Endereço: Rua Fritz Feigl, 465, Rio de Janeiro, RJ, Brasil 22750-600. E-mail:mlseidl@alternex.com.br trabalho insere-se nesse movimento. Visa apresentar uma breve história das principais transformações na concepção da mente nas últimas décadas, e discutir modelos evolucionistas da mente humana.

\section{De Wundt ao movimento cognitivista: a cognição em cena}

As raízes para as abordagens contemporâneas da mente humana que contemplam biologia e cultura podem ser encontradas em discussões filosóficas desde os gregos e através dos séculos, como por exemplo, Platão versus Heródoto, Descartes versus Giambatista Vico, entre outros (Cole, 1998; Seidl de Moura, 1999). Platão inaugura o paradigma que busca conhecer os processos universais da mente humana. Heródoto, um historiador grego, preocupou-se com a questão da origem da disputa entre gregos e persas e, para respondê-la, realizou um dos primeiros estudos de diferentes povos, cujos modos de vida procurou investigar e conhecer. Vico, em contraste com Descartes, propõe que uma ciência unificada não deve adotar o modelo das ciências físicas, mas que a análise histórica da linguagem, dos mitos e de rituais, por exemplo, é o caminho para a compreensão da natureza humana.

Em meados do século XIX, essas raízes podem ser identificadas nos esforços de reconciliação entre as ciências naturais e humanas, como o de J. S. Mill em sua obra $A$ System of Logic, de 1843. Mill já apresenta a proposta de uma ciência com duas facetas, a da psicologia para o estudo das leis elementares da mente e a etologia (do grego ethos, caráter) para o estudo do caráter, considerado como o produto emergente dos pensamentos elementares integrados a circunstâncias locais e individuais. Essa ciência de natureza 
dupla também envolveria uma diversidade metodológica. A experimentação seria reservada à psicologia e seu estudo dos processos elementares. O que seria do âmbito da etologia, ele denomina de "generalizações aproximativas" dos elementos ao todo (Cole, 1998).

A proposta de W. Wundt para a psicologia tem reconhecidamente sido considerada como abordando esses dois aspectos propostos por Mill, embora tenha sido a vertente da psicologia dos processos elementares, ou "psicologia fisiológica", que ficou mais conhecida e que é transmitida com mais freqüência na história oficial da psicologia. A ela Wundt fez acompanhar sua versão de Völkerpsychologie, que incluía a investigação sistemática das origens da mente humana, através do estudo do que denominou de "funções superiores", incluindo, entre outros processos, os da evocação deliberada (memória voluntária), pensamento e linguagem.

Como Mill, Wundt propõe metodologias diversas para esta ciência de duas vertentes. Para a primeira, o uso de experimentos no laboratório e da introspecção controlada com sujeitos altamente treinados nos procedimentos; para a segunda, estudos históricos, lingüísticos e etnográficos. As duas vertentes deveriam ser integradas e indissociáveis, não se reduzindo uma à outra. Além disso, o que é muito pouco discutido na psicologia contemporânea, a völkerpsychologie deveria ter um caráter genético (no sentido de gênese), já que para se estudar os processos mentais superiores faz-se necessário o emprego de uma metodologia evolutiva e histórica. Wundt, no entanto, não tratou da ontogênese, concentrandose na etnologia, que, para ele, consiste no estudo da origem dos povos, acreditando que traria evidência sobre estágios de desenvolvimento mental apresentados pela humanidade.

Ao contrário do que propunha Wundt, para quem essas duas perspectivas deveriam ser articuladas, esta articulação não ocorreu na história da psicologia e até hoje esta tensão entre elas é observada sob diversas formas. Além disso, dificuldades na investigação do pensamento e a busca de consolidação da psicologia como ciência, entre outros fatores, levaram ao desencanto com a possibilidade de estudo científico dos processos mentais "superiores" (Seidl de Moura \& Correa, 1998). Sem entrar nos detalhes dessa parte da história, que não é possível apresentar aqui, esses processos mentais (a cognição humana) passam a ser colocados em uma caixa preta que não é aberta, tanto por reflexologistas como por behavioristas nas primeiras décadas do século xx, por se considerar que não há métodos objetivos e científicos para estudar seu conteúdo. $\mathrm{O}$ objeto da psicologia não é mais a mente, mas reflexos, ou o comportamento humano. $\mathrm{O}$ behaviorismo em suas diversas versões domina o cenário da psicologia americana ou anglosaxônica em geral (Bruner, 1983).

Bruner (1983) comenta que nas décadas de 1930 e 1940 o investigador em psicologia tinha duas opções: o estudo da percepção ou o da aprendizagem. Para ele, os dois caminhos eram diversos: um tinha a ver "com o que o mundo parecia ser e o outro com o que as pessoas faziam como resultado de estarem expostas ao mundo" (Bruner, 1983, p. 67). Essa era a época em que o fisicalismo e a objetividade eram ideais de ciência, e esses caminhos representavam opções epistemológicas diversas. Abraçar o estudo da percepção envolvia uma perspectiva mentalista, fenomenológica e, essencialmente, de influência européia. O estudo da aprendizagem, tentando eliminar toda subjetividade, era dominado pelo behaviorismo e consistia em uma perspectiva fundamentalmente americana e objetiva. Predominavam os estudos de aprendizagem ou os estudos psicofísicos de percepção. O processo psicológico privilegiado era, nessa época, realmente o de aprendizagem como aquisição de respostas.

Mudanças diversas no cenário científico a partir do final da década de 1940 e, principalmente nos anos de 1950 e 1960, como o desenvolvimento da teoria da informação, a lingüística de Chomsky e a ciência da computação, entre outros, levam a uma retomada do estudo da mente humana, particularmente da cognição (Seidl de Moura \& Correa, 1998). Esse conjunto de iniciativas de abertura da caixa preta tem sido denominado de movimento (ou revolução) cognitivista. É caracterizado por algumas tendências, entre elas a da "retomada do conceito de consciência enquanto instância biológica e social, responsável pela doação de sentido aos estímulos que nos atingem" (Penna, 1986, p. 9). Outras características são: a) a concepção do sujeito do conhecimento como ativo e dos processos cognitivos como construtivos, b) a concepção do comportamento humano como intencional e prospectivo (Penna 1984; 1986) e c) a importância que passa a ser atribuída às noções de regras (Chomsky, 1957), planos (Miller, Gallanter \& Pribam, 1960) e estratégias (Bruner, Goodnow \& Austin, 1956).

Uma das contribuições importantes é a de Chomsky, contundente em sua crítica à tentativa de Skinner de tratar linguagem e pensamento como operantes verbais (Chomsky, 1959). Com seus trabalhos, argumenta a favor de uma base inata para a linguagem (Chomsky, 1957), mostrando seu caráter recursivo e gerativo. Sua abordagem caracteriza-se pelo foco na sintaxe (regras que governam as combinações e ordem de palavras permissíveis numa linguagem); ênfase no aspecto criativo da linguagem (idéia de que o número de sentenças possíveis numa linguagem é infinito); visão da linguagem como característica específica da espécie humana; concepção da natureza inata da base para desenvolvimento da linguagem e do papel apenas disparador do ambiente; distinção entre competência e desempenho; definição de linguagem como um sistema abstrato de regras.

A idéia de uma gramática gerativa postulada por Chomsky exerceu influência, principalmente, nos estudos dos processos cognitivos em que o pensamento é focalizado em sua capacidade de processamento lingüístico. Sua concepção da linguagem, como um órgão específico da mente, é tomada e ampliada na visão de "modularidade" de Fodor (1983).

Fodor (1983) pretende descrever uma representação global da organização cognitiva e postula um modelo hierárquico de arquitetura da mente. Esse modelo inclui transdutores, que recebem a informação sensorial, um conjunto de módulos altamente especializados, e um processador central. Os módulos são órgãos mentais, responsáveis por operações específicas e independentes, processando tipos determinados de informação. Evoluíram para processar informação relevante para a espécie, e têm um funcionamento automático, não controlado pelo processador central, fora, inclusive, do controle consciente. Com isso, operam com muita rapidez e eficiência. O princípio que organiza o funcionamento de cada um destes módulos mentais é inato, não dependendo de nenhum tipo de fator exógeno para se desenvolver. 
O desenvolvimento de computadores representou outra vertente que teve forte influência nos estudos cognitivos, servindo como uma nova metáfora para explicar o comportamento humano e os processos psíquicos. Nesse sentido, destaca-se a obra póstuma de Von Neumann (1958), em que a idéia de programas, de operação de memória da máquina, e da possibilidade de construção de máquinas inteligentes são discutidas.

Diversos trabalhos foram importantes para compor o cenário em que a cognição vai assumindo papel de protagonista, como o livro de Miller, Gallanter e Pribam, que trata de "planos e estrutura do comportamento" (Miller \& cols., 1960). Essa obra é representativa das transformações do pensamento psicológico na época. Planos são vistos como um processo hierárquico que pode controlar a ordem em que uma seqüência de operações é executada. Outro trabalho clássico é o de Miller sobre a limitação física da capacidade da memória humana a curto-prazo e sua organização é também de fundamental importância (Miller, 1956).

Iniciativas importantes tiveram lugar na Universidade de Harvard, nos Estados Unidos. Uma delas é a do Projeto Cognição, em que Bruner e colaboradores desenvolvem, a partir de 1952, trabalho sobre o processo de categorização (Bruner, Goodnow \& Austin, 1956). Alguns anos mais tarde, ocorreu a fundação, por Miller e Bruner, do Centro de Estudos Cognitivos, que se tornou pólo de discussões e estudos sobre cognição.

Não são sem divergências, entretanto, as concepções de diversos autores que são considerados atores no movimento cognitivista e que compartilham algumas dessas idéias gerais. Essas divergências podem ser observadas especialmente no que concerne à natureza do ponto de partida do processo de conhecer, e dos limites da construção pelo sujeito. Pode-se observar, nesse sentido, diferenças básicas nas abordagens inatista de Chomsky e Fodor, e a construtivista de Piaget, e de autores como Bruner em posições intermediárias (para uma excelente discussão sobre o tema, vide Piatelli-Palmarini, 1980).

De qualquer modo, o cenário psicológico modifica-se a partir do final da década de 1950 , e, dentro desse movimento cognitivista, de tal maneira se faz o reconhecimento da importância da cognição, que surge uma nova ciência: a ciência (ou ciências, como preferem alguns) da cognição, com a convergência de diversas áreas, como a psicologia cognitiva, ciências da computação e lingüística. O projeto de ciências da cognição não é um projeto unitário, nem do ponto de vista das disciplinas que o compõem nem do referencial teórico que adotam. De comum, pode-se apontar a busca de elaboração de uma teoria sobre a cognição ou, mais especificamente, uma teoria sobre os sistemas inteligentes (Gardner, 1985). Dessa busca resultam modelos de arquitetura cognitiva, ou $d a$ mente, especificando seus componentes fundamentais como sendo um sistema de processamento de informação.

O modelo mais básico e clássico desta arquitetura inclui uma unidade de memória capaz de estocar tanto o programa como os dados, componentes responsáveis pela entrada e saída de informações, e um processador com capacidade para manipular e transformar símbolos num modelo de processamento serial, com a realização de uma operação por vez. Estrategicamente, nesse modelo, são deixados de lado aspectos culturais, de contexto e emocionais: há a decisão deliberada de diminuir a ênfase de certos fatores que podem ser importantes para o funcionamento cognitivo, mas cuja inclusão nesse momento complicaria de forma 'desnecessária'4 o empreendimento científico-cognitivo. Esses fatores incluem a influência de fatores afetivos ou emoções, a contribuição de fatores históricos e culturais e o papel do contexto em que ações e pensamentos particulares ocorrem. (Gardner, 1985, p. 6)

A principal fonte de crítica a este modelo de arquitetura é seu caráter serial. Para os críticos, um sistema inteligente é mais bem representado por um modelo de redes, que dê conta de múltiplas entradas de informação em diversos pontos do sistema, ou seja, em vez de serial, deve ser de entrada e processamento paralelos de informação (Karmiloff-Smith, 1995). Outros ainda, como Bruner (1990), vêem nesse modelo uma versão apenas superficialmente diferente da concepção behaviorista. Independentemente dessas divergências, a cognição humana é tratada pelos modelos computacionais sem considerações sobre seus aspectos funcionais e, nesse sentido, tendo sua história evolucionária ignorada, ou negligenciada.

\section{Modularidade e Fluidez Cognitiva: a Filogênese e a Ontogênese}

\section{O modelo modular de mente}

Apesar do reconhecimento da importância da teoria da evolução das espécies, até recentemente seus princípios e idéias não afetaram de forma significativa a psicologia. Só a partir dos anos de 1990 (Rodrigues \& Otta, 2002), principalmente, observa-se uma renovação do interesse pelas bases biológicas do comportamento humano. Uma das conseqüências dessa tendência foi o surgimento da psicologia evolucionista, que se baseia nos pressupostos da teoria da evolução das espécies de C. Darwin e desenvolvimentos posteriores (neodarwinismo).

Os autores que vêm sendo considerados os pioneiros dessa abordagem (Barkow, Cosmides \& Tooby, 1992) pressupõem a existência de uma natureza humana universal, constituída de mecanismos psicológicos, produtos da evolução. Esses mecanismos são adaptações resultantes de um processo de seleção natural ao longo do tempo evolucionário, ou seja, o modo de vida de nossos ancestrais caçadores-coletores da era pleistocena (Baron-Cohen, 1995).

A psicologia evolucionista integrou a biologia da evolução com a psicologia cognitiva contemporânea. No primeiro caso baseia-se no darwinismo e no neodarwinismo, como já apontado, e no segundo, uma influência importante é a de Fodor (1983), já mencionada, e sua concepção modular da mente humana. A metáfora é computacional, e a arquitetura de mente hipotetizada (como um processador de informações) é considerada resultante da seleção natural.

Na perspectiva de Barkow e cols. (1992), a psicologia evolucionista toma esse modelo modular, considerando a história de espécie. O processador central (inaccessível para

4 A palavra assinalada não aparece grifada no original. 
Fodor) é deixado de lado. É adotada uma perspectiva de alta especialização, de "modularização" maciça, representada pela imagem de um canivete suíço (Evans \& Zarate,1999): uma lâmina para cada aplicação.

É curioso como são abandonados justamente os aspectos mais instigantes da mente, que, como ponderava o próprio Fodor, são seu holismo, "sua paixão pelo analógico" e seu não-encapsulamento. Não é visto lugar para um processador geral, já que se pensa que não há problemas gerais a serem resolvidos. Os problemas de nossos ancestrais eram específicos, por exemplo, detectar predadores, discriminar falsos alarmes, selecionar o alimento adequado, formar alianças sociais, selecionar parceiros etc.

Os módulos propostos são, assim, "ricos em conteúdo". Não fornecem apenas uma sintaxe ou algoritmos para resolver problemas, mas a informação específica que é necessária para cada problema (Mithen, 1998/2002). Como Chomsky (1959) e Fodor (1983), anteriormente, Barkow e cols. (1992) usam o argumento básico da pobreza do estímulo para defender tal tipo de módulos. Segundo eles, não seria possível a aprendizagem de tantos comportamentos complexos por um membro da espécie ao longo do curso da vida a partir apenas de um processador geral.

Os autores evolucionistas propõem um grande número de módulos, entre eles: para reconhecimento de faces, para uso de ferramentas, para relações espaciais, para o medo, para cuidados de crianças, para inferências sociais, para aquisição da gramática, para comunicação e pragmática e para teoria da mente.

Essa "modularização" maciça, sem processamento central é um dos possíveis problemas da concepção de arquitetura da mente da psicologia evolucionista. Rode e Wang (2000) consideram que, além da variedade de definições possíveis do termo módulos, se um modelo estritamente de domínios específicos for pressuposto, fica a questão de como os problemas atuais, com os quais nossos ancestrais não se deparavam, são resolvidos.

Um outro problema é o de que não há lugar no modelo de módulos sem processamento central, para a flexibilidade que caracteriza o funcionamento de nossa espécie, ou para a fluidez cognitiva. Se o funcionamento da mente humana é altamente especializado e produto de módulos selecionados por seu papel na solução de problemas característicos do ambiente evolucionário original, como explicar a capacidade metaprocessual do Homo sapiens sapiens? Por que nascemos com um cérebro ainda por desenvolver-se? Uma visão evolucionista, amparada em evidências de registros fósseis, pode ajudar a superar esse dilema.

\section{Processador central e fluidez cognitiva: duas propostas}

Apesar das divergências, não parece haver atualmente quem rejeite seriamente a idéia de alguma especificidade de processamento em domínios, como os da linguagem, ou de certos padrões, entre eles os que se assemelham a faces, por exemplo. Nesse consenso geral há lugar para muita diversidade, desde autores que defendem a "modularidade" sem processamento central (Barkow \& cols., 1992), a outros que defendem a substituição da hipótese de módulos pela de domínios, mais flexível (Karmiloff-Smith, 1995). Em contraste, no entanto, há autores que defendem a presença e função adaptativa de um processador central na mente do Homo sapiens sapiens. Dois deles serão discutidos aqui.

O primeiro é Merlin Donald (1993). Para esse autor, a mente humana atual co-evoluiu em interação com a cultura e o cérebro, passando por três principais transformações, que envolvem três sistemas de representação mental na memória. Nesse processo, o que foi sistematicamente aprimorado foi a acessibilidade de representações na memória a iniciativas voluntárias, resultando em uma mente "quasi-modular". Resumindo muito a história, o autor propõe que os símios têm uma "cultura episódica". Nela estão presentes capacidades de percepção de eventos, de atribuição social, insight e de "enganar" (deceipt). Há sensibilidade para a compreensão do significado de eventos ambientais e armazenamento em uma memória episódica. Essa capacidade de memória é, entretanto, limitada em termos de recuperação, porque esses animais dependem das pistas do ambiente para a recuperação de representações, já que aprendem sinais, mas não os inventam. Duas áreas de controle motor seriam também limitadas, em comparação com os humanos: a de construção de modelos de ação consciente e a de recuperação voluntária, independente desses modelos.

A primeira transição importante para Donald (1993) foi a do desenvolvimento de uma "cultura mimética". Nela, o controle motor aperfeiçoa-se, já que há a capacidade de modelar ativamente e modificar seu próprio movimento e a de recuperação voluntária de memórias motoras armazenadas, independentemente de pistas ambientais. O tipo de ação envolvido é um sistema unificado supramodal tanto em termos do input como do output, e envolve uma capacidade de usar todo o corpo como dispositivo de comunicação e tradução de percepção de eventos em ação. Com esse sistema ou cultura, houve, segundo Donald (1993), mudanças nos padrões de expressão social dos hominídeos. Assim, as expressões emocionais tornaram-se ampliadas, mais complexas, não estereotipadas e passíveis de serem empregadas na comunicação intencional. Outras conseqüências ou desenvolvimentos paralelos foram a de novas possibilidades de trocas sociais (jogos complexos, competição, pedagogia através de imitação dirigida, diferenciação de papéis sociais, primeiros costumes sociais). Para Merlin, todo esse processo de mimese é uma pré-adaptação para a linguagem.

A segunda transição vai envolver, justamente o que ele denomina de "invenção lexical" e a evolução fonológica, incluindo um conjunto de modificações neuronais e anatômicas específicas. Com o desenvolvimento do sistema lingüístico, o produto coletivo resultante é de um pensamento narrativo e "cultura mítica", e um novo modo de representação compartilhada. Seguindo essa transição, a terceira é no sentido da "externalização" da memória, a partir do desenvolvimento pelos humanos do período paleolítico superior de novos aparatos representacionais, que levam a uma "cultura teórica", que envolve novas propriedades de armazenagem coletiva e de recuperação nos humanos. Isso decorre ou é acompanhado do aumento da plasticidade neocortical que veio com a expansão final do cérebro humano. A mente do Homo sapiens sapiens, então, vai incluir alterações na capacidade de memória de trabalho e o desenvolvimento de habilidades metacognitivas. 
O modelo de Donald (1993) suscitou bastante debate e é discutido por vários autores no volume do periódico em que foi apresentado. Sua visão é da evolução de um processador central, e de capacidades especializadas de representação que se tornaram gradativamente disponíveis na filogênese. Uma das críticas importantes, além da de que o autor não trata de forma totalmente correta evidências paleontológicas (entre outros aspectos por sua formação ser em psicologia), é de que não apresenta explicações funcionais para as transformações e etapas propostas.

As duas críticas não se aplicam ao segundo modelo a ser discutido nesse item. Mithen (1998/2002) é um arqueólogo que apresenta consistente argumentação no sentido de uma mente à qual não se aplica a metáfora do canivete suíço. Para Mithen, o caminho da evolução da mente de nossa espécie apresenta tanto a direção de um aumento da fluidez cognitiva e o desenvolvimento de formas generalizadas de pensamento, como de especialização ou "modularização". Ao contrário do que pensam Barkow e cols. (1992), pondera o autor que: " $o$ passo crucial na evolução da mente moderna foi a mudança de um modelo de tipo canivete suíço para outro com fluidez cognitiva; ou seja, da mentalidade especializada para a generalizada" (Mithen, 1998/2002, p. 321).

Foi justamente essa capacidade de processamento central que possibilitou aos membros da espécie desenvolver instrumentos complexos, criar arte e acreditar em ideologias religiosas. Todas essas propriedades dependem da fluidez cognitiva. Assim, o aumento da fluidez cognitiva e da capacidade de processamento central possibilita a realização desses novos tipos de atividade caracteristicamente humanos. A realização dessas atividades e os produtos dela decorrentes ensejam a disponibilidade de novos contextos de desenvolvimento para os membros da espécie.

Qual, então, o modelo, de arquitetura da mente que foi sendo selecionado? A metáfora de Mithen para a mente do Homo sapiens sapiens é a da catedral, com sua nave central que dá acesso a múltiplas capelas laterais. Essa arquitetura é produto de milhões de anos de evolução, que podem ser sintetizados em três grandes fases (Mithen, 1998/2002).

Nafase 1 a proposta é de mentes regidas por um domínio de inteligência geral, que envolve um conjunto de regras sobre aprendizagem e tomada de decisão. São as mentes dos membros da espécie do ancestral comum aos humanos, símios, macacos e lêmures, que viveu em período anterior a 55 milhões de anos atrás.

A fase 2 é caracterizada por mentes nas quais a inteligência geral foi suplementada por várias inteligências especializadas, que funcionam independentemente e tratam de domínios específicos. O primeiro deles é o da inteligência social, que aparece em período posterior a 55 milhões de anos atrás, e se complexifica entre 35 e 6 milhões de anos. Gradativamente a inteligência geral também aumenta, e os novos domínios, que surgem a princípio relacionados com a atividade de forrageamento, permitem a construção de "grandes bancos de dados sobre a distribuição de recursos" (Mithen, 1998/2002, p. 144). O segundo domínio é o de módulos da inteligência técnica e da inteligência naturalística, na mente dos primeiros Homo, os Homo habilis, entre 4 milhões a um milhão e 800 anos atrás. Entre 1,8 milhões a 100 mil anos atrás, aumentam a inteligência técnica, a complexidade da inteligência naturalística, permitindo a construção de mapas mentais do ambiente e da inteligência social. Acrescenta-se a esses domínios o da linguagem, mas a limitação é a falta de comunicação entre eles, apesar do aumento da inteligência geral.

Finalmente, na fase 3, estão construídas mentes nas quais as múltiplas inteligências especializadas (social, naturalística, técnica e a linguagem) parecem trabalhar juntas, sob a coordenação de uma inteligência geral, havendo comunicação entre os diversos domínios. Essa é a mente do Homo sapiens sapiens, especialmente na transição do período Paleolítico Médio para o Superior. Temos, então, a proposta de um modelo que, como o de Donald (1993), admite a especialização, mas não abre mão de um processo geral de alguma natureza, que apresenta grande flexibilidade e fluidez.

E a ontogênese? Pensar a arquitetura da mente contemporânea pressupõe não só formular hipóteses que não sejam falseadas pelas evidências dos estudos sobre a filogênese, como, ainda, que levem em conta algumas das características da espécie, como a importância da ontogênese.

Barkow e cols. (1992) não parecem atribuir um lugar particularmente interessante para a ontogênese. Consideram que as adaptações psicológicas podem estar programadas para aparecer, desaparecer ou se modificar em momentos diferentes do desenvolvimento, para se imbricar com as demandas específicas das tarefas de cada etapa. Focalizam, principalmente, no entanto, o comportamento e funcionamento mental adulto, não discutindo nenhum processo de construção ou de desenvolvimento ontogenético.

No entanto, é possível ter uma concepção evolucionista da mente atribuindo um papel à ontogênese. Nesse sentido, Keller (2000) propõe que, "desenvolvimento ontogenético é constituído através de um processo ativo de construção, baseado em módulos selecionados evolucionariamente e emoldurado pela teoria de desenvolvimento da cultura" (p. 965).

Duas contribuições no sentido de pensar a ontogênese de uma mente que é produto da filogênese podem ser destacadas: a de Karmiloff-Smith e a de Geary, Bjorklund e Pellegrini (Geary \& Bjorklund, 2000). Karmiloff-Smith (1995, 2000) apresenta um modelo de processo de "modularização" e gradual aumento de disponibilidade de representações. Para ela, apesar de conter predisposições específicas, a mente não é originalmente modular, mas assim se torna com o desenvolvimento. Admite uma quantidade limitada de predisposições inatamente especificadas, que são domínio-específicas. Essas predisposições impõem limites quanto aos tipos de input que a mente processa. A base de sua argumentação é o conhecimento que temos sobre a plasticidade do desenvolvimento inicial do cérebro.

As predisposições inatas são, para Karmiloff-Smith (1995), epigenéticas e envolvem domínios e não módulos (diferentemente do modelo de Fodor). Como foi visto, os módulos ou sistemas de input são geneticamente especificados, com finalidades especiais e funcionam independentemente, focalizando inputs selecionados, e sendo insensíveis a metas cognitivas centrais. São rápidos e seu funcionamento é automático. Os domínios não pressupõem a encapsulação e consistem em um conjunto de representações apoiando uma área específica de conhecimento: linguagem, número, física etc. 
A especialidade de domínios, ao invés de restringir, potencializa o desenvolvimento, permitindo, por exemplo, que o bebê humano aceite inicialmente como input apenas dados que possa ser capaz de computar de forma específica, e limitando a gama de hipóteses a serem consideradas. A partir de delimitações e possibilidades, dados por predisposições inatas tanto específicas como não-específicas, o desenvolvimento se dá por um processo geral, que a autora denomina redescrição representacional, mas não são pressupostas mudanças simultâneas nos diversos domínios.

As experiências são representadas e o conhecimento armazenado na mente toma, segundo a autora, duas direções. Uma é encaminhada no sentido desse conhecimento representado tornar-se cada vez mais encapsulado, mais automático e menos acessível, o que se dá por um processo gradual de "procedimentalização"; outra, ao contrário, de se tornar cada vez mais acessível a outros domínios. Observam-se, assim, os dois movimentos propostos por Mithen (1998/2002) em relação à filogênese: gradual "modularização" e aumento da fluidez cognitiva. As informações inatas e adquiridas são transformadas de forma iterativa pela "redescrição mental" das representações, ou seja, sua reapresentação interna em diferentes formatos. Além disso, com base nas "redescrições representacionais", a informação implícita é transformada em conhecimento explícito, e são observadas a construção consciente e exploração de analogias, experimentos mentais e reais.

Karmiloff-Smith (2000) discute o que seria a mente do bebê "conexionista real", porque adota, com modificações, a versão conexionista das ciências da cognição, aliando-a a uma posição construtivista. Para ela, essa mente incluiria muitas tendências ou predisposições para o processamento de informações, entre elas, redes adequadas para tipos diferentes de input (ex. faces), mas com especificações deixadas em aberto. O cérebro do bebê teria, assim, limites ou especificações de arquitetura, mas sem conteúdo representacional. As representações emergiriam das interações entre esses limites de arquitetura e a estrutura de tipos diferentes de input (ex. em relação a faces, a aprendizagem das características de diferentes tipos de faces). As redes aprendem (modificam-se) ao assimilar o input que é processado e ao incorporar as mudanças representacionais decorrentes da estrutura do input, e essa aprendizagem dá-se lentamente. A representação emerge das atividades da rede. Para Karmiloff-Smith (2000), com esse modelo, pode-se repensar a questão do inatismo.

A segunda vertente de contribuições vem de autores que desenvolveram um ramo específico da psicologia evolucionista, cuja influência vem crescendo na última década, e que têm produzido um conjunto de publicações recentes: o da psicologia do desenvolvimento evolucionista. Esta disciplina focaliza o estudo da manifestação no curso da ontogênese, sob a forma de comportamentos ou mecanismos psicológicos, dos programas que evoluíram em interação com os ambientes social e físico.

Esses mecanismos são bastante sensíveis às variações do ambiente. A idéia é que os organismos (humanos, nesse caso) afetam o ambiente escolhendo e preenchendo seus nichos e o ambiente afeta os organismos levando a mudanças em comportamentos para atender a características específicas desses nichos. O desenvolvimento das características fenotípicas humanas e as variações individuais no comportamento são, assim, produto de uma interação de mecanismos genéticos e ecológicos, envolvendo as experiências únicas de cada indivíduo desde antes do nascimento. Os autores (Geary \& Bjorklund, 2000) também apresentam uma perspectiva tanto de domínios específicos como de processamento central.

\section{Considerações Finais}

As discussões e possibilidades de formulação de hipóteses explícitas a partir dos modelos de mente aqui apresentados são inúmeras e fascinantes, tanto em termos da ontogênese, como, indiretamente, da filogênese. As inteligências de Mithen podem ser vistas como englobando alguns módulos ou domínios específicos. É possível que a inteligência social, por exemplo, envolva as capacidades iniciais dos bebês humanos para discriminar e responder diferencialmente a estímulos relacionados a co-específicos (ex. faces, vozes), e a ligar-se a seus cuidadores. Como o ambiente social dos primatas e, particularmente dos humanos, é complexo, para sobreviver e ter boa aptidão reprodutiva, é necessário não só ser protegido pelos cuidadores, mas aprender nesse ambiente social. Para isso, o desenvolvimento da atenção conjunta é fundamental. Essa é uma área de investigações muito fértil atualmente e em que há ainda controvérsias. Para alguns, como Baron-Cohen (1995), alguns dispositivos inatos e característicos da espécie existem e são produtos da seleção natural: o mecanismo de detecção da direção do olhar (EDD - Eye direction detector), o dispositivo de atenção conjunta (SAM - shared attention mechanism), o mecanismo de teoria da mente (TOMM - theory of mind mechanism). Para outros, há uma capacidade de intersubjetividade primária inata (Trevarthen, 1979). Outros ainda, como Tomasello (1999), mesmo não negando programas abertos iniciais, atribuem papel fundamental à aprendizagem cultural. De qualquer maneira, é importante formular e testar hipóteses específicas nessa área (e em quaisquer outras), pensando em um modelo de mente que é produto da evolução da espécie humana.

Em síntese, observa-se que, com a abertura da caixa preta, o movimento cognitivista talvez tenha aberto uma Caixa de Pandora, que traz muitos questionamentos e controvérsias ainda não resolvidas. A tendência inicial da ciência da cognição foi, em certos termos, cautelosa, excluindo a emoção, a cultura e qualquer explicação funcional. A história ou pré-história da mente, deixada de lado pelos cientistas da cognição, logo é incluída nas discussões pelos psicólogos evolucionistas. Nesse percurso de história de busca de compreensão da mente humana, sínteses parciais são propostas, mas é necessário ampliá-las. Essa ampliação vem pela consideração da ontogênese e pela entrada em cena das neurociências, que não foram tratadas neste artigo. Com esse último movimento, observa-se a superação do dualismo mente $\mathrm{x}$ cérebro, e uma tendência a dar o próximo passo importante: o da não-separação entre razão (cognição) e emoção. Essa é uma outra história, mas pode-se terminar aqui com uma visão otimista dos rumos que essa história está tomando, e com a convicção de que o lugar da mente em estudos científicos não é em nenhuma caixa preta. 


\section{Referências}

Barkow, J. H., Cosmides, L. \& Tooby, J. (Orgs.). (1992). The adapted mind. Oxford: Oxford University Press.

Baron-Cohen, S. (1995). The Eye Detection Detector (EED) and the Shared Attention Mechanism (SAM): Two cases for evolutionary psychology. Em P. Rochat (Org.), Early social cognition: Understanding others in the first months of life (pp. 41-60). Mahwah, NJ: Lawrence Earlbaum.

Bruner, J. (1983). In search of mind: Essays in autobiography. New York: Harper \& Row.

Bruner, J. (1990). Acts of meaning. Cambridge, Mass. \& London: Harvard University Press.

Bruner, J., Goodnow, J. \& Austin, G. (1956). A study of thinking. New York: John Wiley.

Chomsky, N. (1957). Syntactic structures. The Hague: Mouton.

Chomsky, N. (1959). Review of B. J. Skinner's Verbal Behavior. Language, 31(1), 26-58.

Cole, M. (1998). Cultural psychology: A once and future discipline. Cambridge: The Belknap Press of Harvard University Press.

Donald, M. (1993). Précis of origins of the modern mind: Three stages in the evolution of culture and cognition. Behavioral and Brain Sciences, 16(4), 737-791.

Evans, D. \& Zarate, O. (1999). Introducing evolutionary psychology. Cambridge, Mass.: Icon Books.

Fodor, J. (1983). The modularity of mind. Cambridge, Mass.: MIT/Bradford Press.

Gardner, H. (1985). The mind's new science: The history of the cognitive revolution. New York: Basic Books.

Geary, D. C. \& Bjorklund, D. F. (2000). Evolutionary developmental psychology. Child Development, 71(1), 57-65.

Karmiloff-Smith, A. (1995). Beyond modularity: A developmental perspective on cognitive science. Cambridge, Mass: MIT Press.

Karmiloff-Smith, A. (2000). The connectionist infant: Would Piaget turn in his grave? Em A. Slater \& D. Muir (Orgs.), The Blackwell reader in developmental psychology (pp. 43-52). Oxford \& Massachusetts: Blackwell.

Keller, H. (2000). Human parent-child relationships from an evolutionary perspective. American Behavior Scientist, 43(6), 957-969.

Miller, G. A. (1956). The magical number seven, plus or minus two. Psychological Review, 63(1), 81-97.

Miller, G. A., Gallanter, E. \& Pribam, K. (1960). Plans and the structure of behavior. New York: Holt, Rinehart \& Winston.
Mithen, S. (2002). A pré-história da mente: Uma busca das origens da arte, da religião e da ciência. (L. C. B. de Oliveira, Trad.) São Paulo: Editora da Unesp. (Trabalho original publicado em 1998)

Penna, A. G. (1984). Introdução à psicologia cognitiva. São Paulo: EPU.

Penna, A. G. (1986). Cognitivismo, consciência e comportamento político. São Paulo: Vértice.

Piatelli-Palmarini, M. (Org.) (1980). Language and learning: The debate between J. Piaget and N. Chomsky. Cambridge, Mass.: Cambridge University Press.

Rodrigues, M. M. P. \& Otta, E. (2002). Desenvolvimento sócioafetivo de bebês: Alguns fundamentos evolutivos. Em A. S. Molina, A. M. Carvalho, E. Otta, E. Suyama, L. M. Simão, M. M. P. Rodrigues, M. T. C. C. Souza, M. G. M. Machado, P. de S. Oliveira \& V. S. R. Bussab (Orgs.), Cultura, cognição e afetividade: A sociedade em movimento (pp. 69-84). São Paulo: Casa do Psicólogo.

Rode, C. \& Wang, X. T. (2000). Risk-sensitive decision making examined within an evolutionary framework. American Behavior Scientist, 43(6), 926-939.

Seidl de Moura, M. L. (1999). Interações iniciais e seu papel no desenvolvimento: Uma contribuição ao estudo da atividade mediada. Tese de Titular, Universidade do Estado do Rio de Janeiro, Rio de Janeiro.

Seidl de Moura, M. L. \& Correa, J. (1998). Estudo psicológico do pensamento: De W. Wundt à ciência da cognição. Rio de Janeiro: EdUERJ.

Tomasello, M. (1999). Social cognition before the revolution. Em P. Rochat (Org.), Early social cognition: Understanding others in the first months of life (pp. 301-314). Mahwah, NJ: Lawrence Earlbaum.

Trevarthen, C. (1979). Communication and cooperation in early infancy: A description of primary intersubjectivity. Em M. M. Bullowa (Org.), Before speech: The beginning of interpersonal communication (pp. 321-347). Cambridge: Cambridge University Press.

Von Neumann, J. (1958). The computer and the brain. New Haven, Connecticut: Yale University Press.

Recebido em 21.12.2004

Primeira decisão editorial em 31.05.2005

Versão final em 16.06.2005

Aceito em 20.07.2005 